\title{
A system dynamics approach to examining household food insecurity
}

\author{
Kyle R. Metta ${ }^{a} *$ and Laura Schmitt Olabisi ${ }^{b}$ \\ Michigan State University \\ Renee V. Wallace ${ }^{\mathrm{c}}$ \\ FoodPLUS Detroit
}

Submitted July 19, 2019 / Revised August 31, October 21, and November 23, 2020 /

Accepted November 23, 2020 / Published online March 31, 2021

Citation: Metta, K. R., Olabisi, L. S., \& Wallace, R. V. (2021). A system dynamics approach

to examining household food insecurity. Journal of Agriculture, Food Systems, and Community

Development, 10(2), 455-472. https://doi.org/10.5304/jafscd.2021.102.028

Copyright (C) 2021 by the Authors. Published by the Lyson Center for Civic Agriculture and Food Systems. Open access under CC-BY license.

\begin{abstract}
Household food security is influenced by the socio-political environment, resource access, and experiential factors, but the systemic interactions of these drivers are rarely considered in the same study. In collaboration with stakeholders, we built a system dynamics model to examine the drivers of food insecurity in Detroit and how community-led interventions could promote food security. We
\end{abstract}

\footnotetext{
a* Corresponding author: Kyle R. Metta, Ph.D., Department of Community Sustainability, Michigan State University.

Dr. Metta is now Community Systems Postdoctoral Fellow, Center for Community Health and Development, University of Kansas; Dole Human Development Center; 1000 Sunnyside Avenue; Lawrence, KS 66045 USA; kmetta@ku.edu

b Laura Schmitt Olabisi, Ph.D., Associate Professor, Department of Community Sustainability, Michigan State University; 138 Natural Resources Building; East Lansing, MI 48824 USA; Schmi420@msu.edu

${ }^{\mathrm{c}}$ Renee V. Wallace, Executive Director, FoodPLUS Detroit; 18452 Monte Vista; Detroit, MI 48221 USA; Renee@,FoodPlusDetroit.org
}

found that single interventions were not as effective as multiple interventions in combination, due to the complex limits on a households' ability to purchase healthy foods. The iterative modeling process allowed stakeholders to jointly understand and generate insights into the cross-scale limits that households must navigate in order to achieve food security. Furthermore, our modeling effort demonstrates how time is a fundamental resource stock that limits the efficacy of behavioral and structural interventions.

\section{Keywords}

Food Security, System Dynamics, Urban Food Systems, Participatory Modeling

\section{Funding Disclosure}

This research was funded by a grant from Michigan State University's Applied Public Policy Research Program (MAPPR) facilitated by the Institute for Public Policy and Social Research (IPPSR). This program is made possible through funding allocated by the State of Michigan to develop expertise for Michigan's policymaking community. 


\section{Introduction}

Recent food security literature has stressed the necessity of a systems approach to understanding the complex nature and interconnections between the food system and public health outcomes (Story, Hamm, \& Wallinga, 2009). Though systems approaches have been applied to these intersections (Conner \& Levine, 2007; Fleischer et al., 2017), this work has primarily been qualitative. A quantitative systems approach has the advantage of allowing users to test system interventions, analyze system behavior over time, and understand complex interactions. The food systems literature has come to be more integrated with the complex systems and socio-ecological resilience literature, particularly at regional scales (Hodbod \& Eakin, 2015; Lamine, 2015). This presents a potential framework for a better understanding of how social and ecological interactions produce different food security outcomes. However, this integration is still rare at the scale of an urban community, a setting in which many food security interventions are targeted.

A household's food security status, one contributing factor to healthy living, is a complex problem. It is shaped by the interactions between its resources and the broader food environment (Campbell, 1991). Households are embedded in larger systems that include cultural factors and determine physical access to food retailers, and thus the availability of healthy foods. Food environments and physical access to food retailers have become emerging areas of study, engendered by the concept of food deserts (Beaulac, Kristjansson, \& Cummins, 2009; Guy, Clarke, \& Eyre, 2004; McKenzie, 2014). Though the food desert literature has its critiques and limitations (Wrigley, Warm, Margetts, \& Whelan, 2002), many empirical studies have concluded that there is a relationship between physical access to full-service grocery retailers and nutrition-related health outcomes (Hendrickson, Smith, \& Eikenberry, 2006). One area improving our understanding of urban food security is research on food environments, which includes measures of market composition mix between healthier and less healthy options and assessments of how households access food vendors (Widener, Farber, Neutens, \& Horner, 2013; Wrigley, Warm, \& Margetts, 2003; Zenk et al.,
2009). There have also been recent attempts in the behavioral health literature to better understand the effect that perceptions of time scarcity have on food consumption choices.

In this article, we examine how urban food insecurity and its risk factors manifest and persist in Detroit, MI. We use a participatory system dynamic modeling approach to focus on how the complex interactions between household resources and the broader food system generate patterns of food (in)security. In doing so, we take an interdisciplinary methodology, integrating empirical and theoretical knowledge with insights from food system practitioners. The resulting model is then used to develop and test interventions and analyze potential leverage points.

Urban food insecurity is driven by characteristics of the food environment and individual household resource constraints (Beaulac et al., 2009; Campbell, 1991; Walker, Keane, \& Burke, 2010). Campbell (1991) presents a food security framework that distinguishes between the experiential dimensions of food access and the social context of food security. Here, experiential aspects are used to explain the outcomes of diet sufficiency and its effects on health and quality of life. In this conceptualization, a household's resources are a product of, and often defined by, the dynamics of larger community systems - the local economy, labor market, education, and nonfood expenditure prices of housing, taxes, etc. These households exist within the larger food system and the local food environment. The food environment is characterized by relative access to food outlets and retailers and the quality of the available products.

In a systematic review of food access, Beaulac and colleagues (2009) find that "evidence is both abundant and robust enough for us to conclude that Americans living in low-income and minority areas tend to have poor access to healthy food" (p. 4). Hendrickson et al. (2006), studying food in urban grocery stores, discover that prices are higher, and food quality is poorer, in areas with high poverty. Additionally, there is less quantity and variety offered at stores in these areas. The authors also find that food prices in the urban food desert are higher than in suburban neighborhoods (Hendrickson et al, 2006). 
Lack of transportation is a barrier to food access. Many low-income households lack access to cars and are unable to afford the costs of getting to larger supermarkets outside of their immediate neighborhoods (Guy et al., 2004; Hendrickson et al., 2006; Rose \& Richards, 2004). Hillier, Cannuscio, Karpyn, McLaughlin, Chilton, and Glanz (2011) find that low-income parents travel further than other low-income groups to shop for food. Clifton (2004), in a case study examining mobility strategies for low-income food shoppers, found that the most common and useful approach is for households to purchase a vehicle for transportation (Clifton, 2004). The interaction of spatial proximity and how people access food through the transportation system is being addressed by some researchers including spatial-temporal measurements in food environment studies (McKenzie, 2014; Rose \& Richards, 2004; Widener et al., 2013).

Behavioral health researchers have investigated how perceptions of time scarcity affect food consumption choices. Furst, Connors, Bisogni, Sobal, and Falk (1996) developed a conceptual model of food choice-making, documenting that time, as a resource stock, influences food choices. In a review of the literature on perceptions of time scarcity and food choices, Jabs and Devine (2006) document the growth in interest to further understand how time influences decision-making around food. They document how changes to intrafamily dynamics have influenced meal planning and how these changes are due to added time pressure (Connors, Bisogni, Sobal, \& Devine, 2001; Furst et al., 1996). Time scarcity is linked to obesity (Cawley, 2004) and the rapid sale of convenience products, including convenience food (Gofton, 1995). Sales of convenience foods are on the rise (Jekanowski,

Figure 1. Study Design

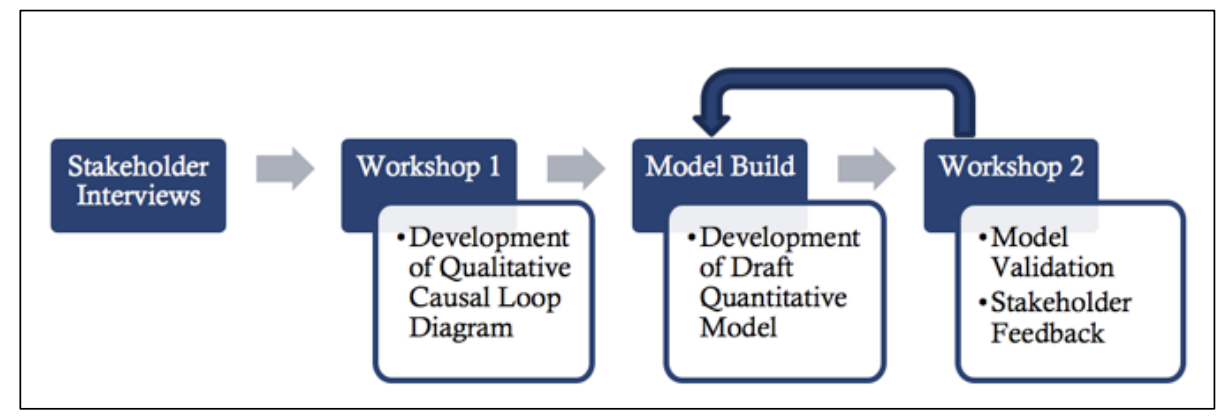

1999); fast food sales have increased for lowincome households; and convenience foods and foods eaten outside of the home have lower nutritional value (Guthrie, Lin, \& Frazao, 2002).

Much of the reviewed literature has called for systems thinking around food and nutrition security (Fleischer et al., 2017; Lamine, 2015; Story et al., 2009; Walker et al., 2010). The community food security literature states that to conquer food insecurity, it is necessary to address governance systems first (Bellows \& Hamm, 2002; Hamm \& Bellows, 2003; Pothukuchi, 2011). Campbell's food security framework emphasizes the interconnectedness of systems and household resources and the systemic barriers to achieving security (Campbell, 1991). In a review of the literature on food security and health disparities, Walker et al. conclude by recommending "an innovative method such as concept mapping, a participatory research method that allows hypotheses to be generated" and using the data to provide "understanding of the complexity of food access and the food environment, while providing a basis for program planning and policy development aimed at addressing access to healthy and affordable foods" (Walker et al., 2010, p. 882). Such a method would allow the integration of the different insights into the causes of food insecurity discussed above. In this paper, we heed Walker and colleagues' (2010) recommendation.

\section{Research Design and Methods}

For this research, we partnered with FoodPlus Detroit and the Detroit Food Policy Council to identify a meaningful problem statement. We worked with our community partners to design the research process illustrated in Figure 1. The research began by identifying and interviewing key stakeholders in Detroit who have experiential knowledge of the systems governing food insecurity. The semistructured interviews focused on barriers to household food security in the city as well as possible interventions to minimize them. We then 
conducted a workshop in Detroit to construct a qualitative model of the system. We used this system diagram and the interviews to develop a quantitative system dynamics model of urban food security. We demonstrated and validated this model with community stakeholders in a second workshop and received feedback on its assumptions and behavior.

\section{Interviews}

Our community partners identified 15 key stakeholders to include in the semistructured interview sessions. Stakeholders were affiliated with or represented interests from urban agriculture, local government, food sales and distribution, economic development, emergency food services, small business owners, and entrepreneurs (see Appendix A for the full list). The interviewees were prompted with questions that focused on the patterns and drivers of food insecurity over time (see Appendix $\mathrm{B}$ for the interview structure). Our goal was to elicit comments that would inform the system structure. We also inquired into perceptions of proposed solutions. We also asked about views of the future and if the participants expected things in the food system to improve, worsen, or stay the same. This process was conducted to prime participants to think about the systemic issues governing food security in their communities. The data were used to inform the quantitative system dynamics model and the scenarios tested in Section 4.

\section{Participatory Model Building}

Participatory modeling or Group Model Building (GMB) is a tool that has been used to mediate consensus and understanding of a problem statement (Hovmand, Ford, Flom, \& Kyriakakis, 2009; Van den Belt, 2004). It is useful when multiple stakeholders hold competing mental models of how a system operates (Hirsch, Levine, \& Miller, 2007; Olabisi, 2013; Van den Belt, 2004). Like traditional system dynamics modeling, it utilizes a simulation tool to examine the behavior of complex systems over time (Olabisi, 2013; Sterman, 2000). Its main features are the ability to represent feedback (circular causal relationships) and stockand-flow dynamics. Through simulation and informal maps, the models assist with under- standing the endogenous sources of system behavior. Participatory system dynamics modeling has been used to rigorously test the implications and effectiveness of policy interventions at community, state, and national levels (Olabisi, 2013; Stave, 2002; Stave, 2003; Van den Belt, 2004).

Causal Loop Diagrams (CLDs), which form the conceptual basis for a system dynamics model, can be used to illustrate and document the causal mechanisms and feedbacks governing a system (Kirkwood, 2013; Sterman, 2000; Van den Belt, 2004). Creating CLDs is a process that explicitly lays out assumptions of causal relationships and identifies any mutually causing variables, or feedback (Sterman, 2001).

\section{Causal Loop Diagrams}

Workshop 1 of our research design centered around diagramming potential barriers to food security in Detroit. With guidance from our community partners, we invited 16 stakeholders with unique and experiential knowledge of the food system to participate. Workshop 1 began with the focal question: What are the drivers of food insecurity in Detroit? This focal question was open to different scales of analysis (community, household, etc.). The workshop allowed stakeholders to work in small groups to diagram and map their perceptions of the system structure. The small groups worked independently, with assistance from facilitators who answered technical questions. The small groups then explained their diagrams to the larger group for input, critique, and clarification. The modeling team then worked to integrate and aggregate the diagrams into a qualitative model. This iterative process resulted in Figure 2. Fully assembled, the qualitative model documents 15 feedback loops, 13 of which are reinforcing, and two of which are negative or balancing. The diagram represents the stakeholder views of the system and its causal mechanisms.

There are four segments of the aggregated CLD addressing the multiple broad areas that the group identified. These segments, which are found in the aggregate diagram, have been identified as the Home-Economic, Cultural-Nutritional, SocioPolitical, and Peer Network segments (see Appendix for CLD Segment descriptions and diagrams). 
Each segment has specific features and drivers operating at different scales. Though some of the segments deal with macro-level system behavior, all groups identified how the processes affect community and household food security.

\section{Quantitative Model}

We used the qualitative CLD (Figure 2) to inform the creation of a quantitative system dynamics model (Kirkwood, 2013). The CLD demonstrates how the system is operating at two scales: the larger community food system and the dynamics influencing household food security. We chose to build the quantitative model at the household level as there was significant interest from our community partners in how policy interventions affect household food security. It was also believed that the model output at this scale would inform immediate policy considerations and be more easily understood by community members and associated practitioners.

\section{Model Description}

The system dynamics model depicts a single household in the city of Detroit. The household is programmed to make food purchasing and consumption decisions for different types of food products. The household attempts to fill its food pantry stock by purchasing "healthy food" or "convenience food." It is constrained, however, based on available income and time. The time constraint is introduced by the physical distance of the household from produce vendors, and the type of transportation available to the household. The model uses the daily recommended consumption of fresh fruits and vegetables (FF\&V) as a proxy for "healthy" food consumption (U.S. Department of Health and Human Services \& U.S. Department of Agriculture, 2015). A list of all model equations can be found in Appendix C.

The modeled household makes two decisions every time step: the type of food to purchase and the type of food to consume. The purchasing decision functions by maximizing the fulfillment of healthy food preferences (which are influenced by the broader culture, peer influence, and the alternative food economy), given the constraints of time and income. The consumption decision is a function of current food stocks, current time stocks, and the household's perception of time

\section{Figure 2. Aggerate Causal Loop Diagram}

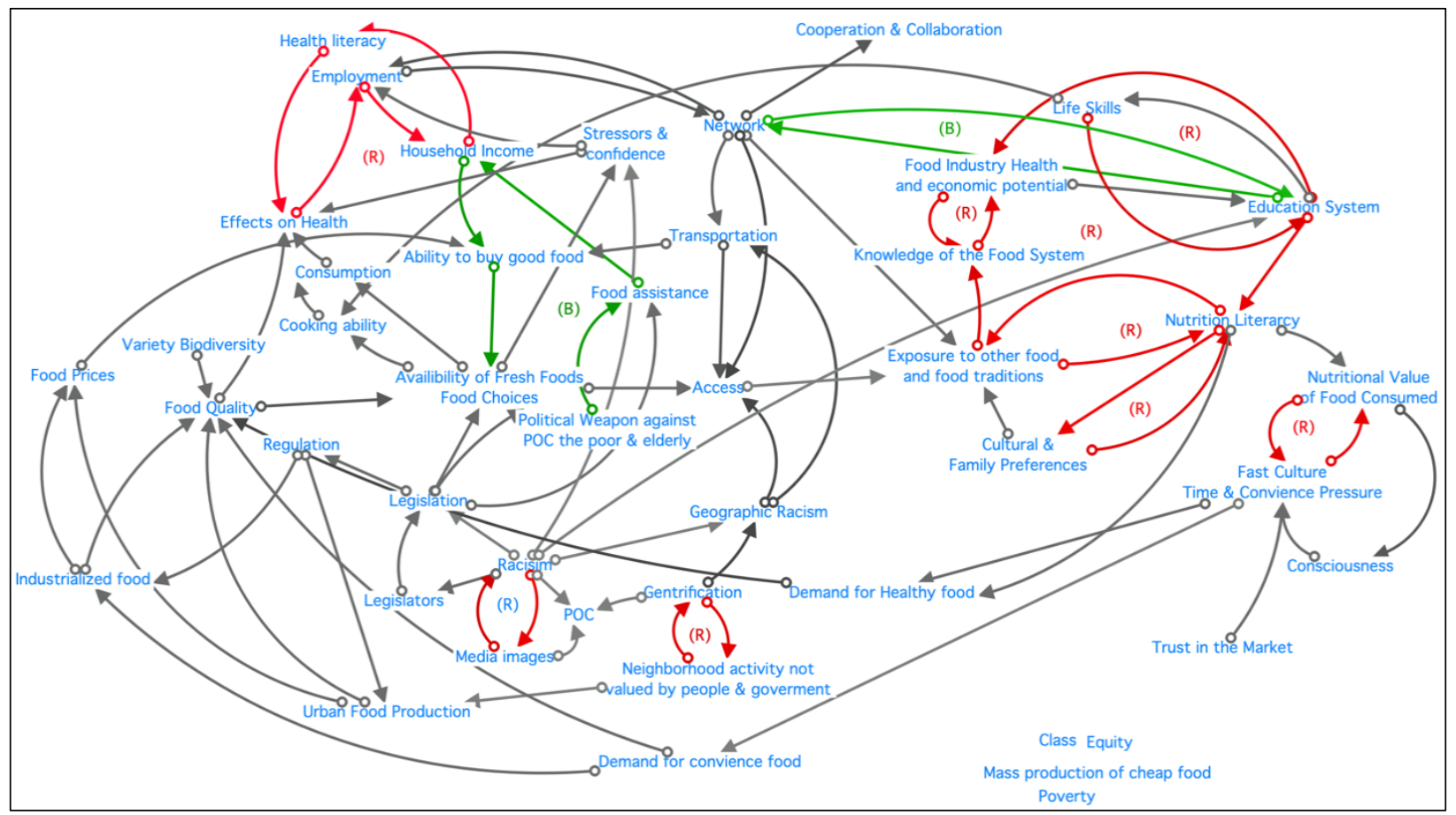


scarcity. The household's time perception is a sigmoidal function that depicts the relationship of available free time and healthy food consumption. When time is more open, the household attempts to consume healthier food, as long as healthy food stocks are available and desired. Convenience foods represent highly processed or prepared foods that save time (Brunner, van der Horst, \& Siegrist, 2010). If the household is low on time, they will eat these foods (if they are available in the pantry). Alternatively, if the household does not have enough food to eat, they will consume emergency food, which represents any food security coping strategy (not eating, going to a soup kitchen, food bank, eating at a friend or relative's, etc.) (Maxwell, 1996). If the household is low on time and does not have enough convenience food, they will consume a prepared meal or an "away-from-home meal" or, in some cases, "fast food" (Stewart, Blisard, Bhuyan, \& Nayga Jr, 2004).

The model takes into account a simplified version of the food system, including the proximity of retail grocery stores, the amount of available alternative food system options (community gardens, farmers markets, CSA), and the effects of peer influence. These broader food system influences are also affected by the household's preferences, as there is a reinforcing feedback loop between household preference for fresh fruits and vegetables and the growth rate of the alternative food system.

The model functions within six modules: Home Economics, Time Cost, Nutritional Security, Preference for Fresh Fruits \& Vegetable, Alternative Food Economy, and Retail Food Environment. The Home Economics module is where the household sells their labor-time on the market and receives a wage. This module structures the amount of money that can be allocated for food, housing, transportation, and bills, and receives feedback by way of a Health Event from the Nutritional Security Module. The Nutritional
Security module is where the purchase and consumption decisions are made. This module uses inputs generated from the other modules and follows simple rules for allocating resources. It has a reinforcing feedback loop with the Home Economics model; more income for food leads to a higher level of nutritional food security, which leads to a more stable availability of labor (time) and income for food (minus health-event costs). There is also a balancing feedback loop: if income increases through working overtime, this reduces the time stock, and therefore, nutritional security.

\section{Home Economics Module}

The Home Economics Module follows a stockflow diagram that tracks the Household's monthly income and income allocated for food. Income is generated through labor, and the costs of this labor (e.g., commuting) are also included in the outflow expenses. The household first pays its housing and transportation costs before allocating money for food. ${ }^{1}$ Transportation expenses include gas and monthly payments for car servicing, insurance, and leasing. This function can be toggled off, which defaults the model to use public transportation. This option requires more time but is significantly cheaper.

This food money then flows into a stock called Income for Food, which also has an inflow of Food Assistance, calculated using the USDA methodology for Supplemental Nutrition Assistance Program benefits (U.S. Department of Agriculture, Food and Nutrition Service, n.d.). Money spent on food is generated in the Nutritional Security Module and represents what the house is spending per month on food. There is also an expense labeled Health Event, which deducts money each month if a family member is sick or injured, which may cost a family working hours. There are of course other expenses that may be related to a health event (medical expenses, child care, etc.); however, these expenses occur outside the boundary of the

\footnotetext{
${ }^{1}$ This is a simplifying assumption and limitation imposed by the modeling process. In system dynamics modeling, there must be a "flow priority" when there are multiple flows out of a stock. Allowing the model to draw down the income stock with nonfood items first allows the impacts of variability to be shown through the lens of food security outcomes. If we reversed this priority, having the household draw down the income stock with food-related expenses first, we would have to expand the model to include indebtedness, late-fees and penalties, and possible housing evictions, which was out of scope for the purposes of this model.
} 
represented cash-flow system. The module is defaulted to use an hourly workweek, which is highly variable, between 120 and 200 hours a month, representing that many hourly employees have inconsistent scheduling and income.

\section{Time Cost Module}

The Time Cost module uses a simple stock-flow structure to depict a household's available time. Each month, 720 hours are added to the time stock. The time stock is depleted by work hours, commuting hours, and other time (where food decisions are made). The model calculates commute time by dividing hours worked in the month by an eight-hour shift for commutes and multiplying by the median distance traveled for work in Detroit. Speed is captured in the Car Speed and Public Transportation Speed converters, which are $45 \mathrm{mph}$ and $15 \mathrm{mph}$ respectively.

\section{Preference for Fresh Fruits and Vegetable Module}

The Preference for Fresh Fruits and Vegetable module is where the household preference for healthy food is modeled. This preference represents a goal that the Nutritional \& Food Security Module uses to calculate purchasing decisions. The dynamics of this module are influenced by healthy eating education programs, peer behavior, cultural impacts, and the level of household exposure to healthy options. Though this preference goal is not updated based on food security outcomes, it is influenced by the balancing dynamics of the larger food system culture and growth of the Alternative Food Economy (AFE).

\section{Nutritional Security Module}

The Nutritional Security Module is where the household makes decisions about which food to purchase and which foods to consume. It is a biflow relationship between two pantry stocks called Healthy Food and Convenience Food. These stocks are calculated in meals. Meals are purchased (inflow) once a month and consumed (outflow) at a rate of three meals a day per household member.

\section{Purchasing}

The inflows follow a simple set of rules for how the Household will purchase food. It assumes that the household is trying to maximize its fulfillment of healthy food preferences and purchase healthy foods given the constraints of time and income. Here, maximizing the fulfillment of healthy food preferences does not mean that the household is trying to consume as much healthy food as possible; rather, the household is attempting to purchase the amount of healthy food it desires, which could be zero. The purchase quantity is limited to 45 meals a trip if the household does not have access to a car. Convenience foods are purchased at a quantity that satisfies the need to replenish the total stock of meals per month. Convenience meals purchased are a function of healthy meals purchased in the same time period. To illustrate this relationship, if the household is one member; they require 90 meals per month. If they purchase 30 healthy meals in a month, the model purchases up to 60 convenient meals, if the income for food is available. The household also tries to maximize its healthy meal preference fulfillment through consumption, which is limited by time and Healthy Meal stocks. We used a graphical function that illustrates the perceived time one needs to prepare food, which we derived from the American Time Use Survey. Convenience meals consumed is also a function of the healthy meals consumed, much like the purchase function. Besides going hungry, the household follows two more rules to satisfy their food needs. If they have low time and healthy foods, the household can consume food outside the home ('fast food'). If they have time and inadequate meals in their pantries, they seek emergency food, which can be part of an array of different coping strategies.

\section{Model Demonstration and Validation}

The second workshop was designed to demonstrate the quantitative system dynamics model to community stakeholders and elicit feedback on the model behavior and assumptions. A graphical user interface (GUI) was designed to allow the stakeholders to interact with and navigate the model firsthand. The GUI connected model parameters to sliders and buttons, making it simple to change assumptions and analyze the results. Stakeholders were encouraged to make hypotheses about system behavior and to test these with the model. 
From the GUI display, stakeholders could also select critical interventions which the modeling team made accessible with a single click. These interventions were designed with information from the stakeholder interviews about possible solutions to food insecurity. Table 1 describes these interventions and their operations. The stakeholders were prompted to create their own 'on-the-spot' interventions and test them with the model. Participants also gave feedback on the model and its assumptions to validate the model accuracy and improve the model structure.

The model was tested with other standard validity methods (Barlas, 1996; Sterman, 2001). The equations were reviewed for consistency with the CLD and stakeholder interviews. The model was checked for consistency of units throughout. It generated reasonable behavior for a wide range of parameter values, including for extreme conditions.

\section{Results}

Reference Mode

A system dynamics model's reference mode is used to illustrate the problem statement that the modeling effort seeks to examine (Sterman, 2000). For this modeling effort, we are tracking a household's consumption of fresh fruits and vegetables, which serves as a proxy for the nutritional quality of all meals consumed. The model measures food consumed, instead of traditional food security measures like food access, to examine the experiential and behavioral dimensions of food and nutritional security.

The reference mode is run with no interventions and is parameterized to represent a typical household in Detroit. The median household income for Detroit (US\$26,325) and the median commuting time (26.6 minutes one way) are used

\section{Table 1. Interface Intervention Definitions}

\begin{tabular}{|c|c|c|}
\hline \multirow[t]{2}{*}{ Hourly Employee } & $\begin{array}{l}\text { Condition } \\
\text { On * }\end{array}$ & $\begin{array}{l}\text { What it does } \\
\text { Assumes the employee works a variable hour } \\
\text { workweek between } 30 \text { and } 50 \text { (over } 40 \text { is } 1.5 \text { rate of } \\
\text { pay) } \\
\text { Consistent } 40 \text { workweek, no overtime }\end{array}$ \\
\hline & Off & Consistent 40 workweek, no overtime \\
\hline \multirow[t]{2}{*}{ Owns Car } & On* & $\begin{array}{l}\text { Household Owns a car, paying monthly fixed costs } \\
\text { and mileage }\end{array}$ \\
\hline & Off & $\begin{array}{l}\text { Household uses public transportation, taking twice } \\
\text { the time, and limiting how much food can be } \\
\text { transported in a single trip }\end{array}$ \\
\hline \multirow[t]{2}{*}{$\begin{array}{l}\text { Healthy Food Time } \\
\text { Priority }\end{array}$} & On & $\begin{array}{l}\text { Graphical function. Time preference for purchasing } \\
\text { and preparing healthy food is a priority. }\end{array}$ \\
\hline & Off* & $\begin{array}{l}\text { Graphical function. Time preference is consistent } \\
\text { with time-use averages. As perceived time lessons, } \\
\text { the preference to prepare healthy food declines. }\end{array}$ \\
\hline \multirow[t]{2}{*}{ Healthy Eating Education } & On & $\begin{array}{l}\text { An intervention that increases the household } \\
\text { preference for purchasing healthy food. }\end{array}$ \\
\hline & Off* & No increase in healthy eating preference. \\
\hline Education Strength & Input & $\begin{array}{l}\text { Input how effective the education intervention was, as } \\
\text { a percent increase in preference as an annual increase. }\end{array}$ \\
\hline \multirow[t]{2}{*}{ Healthy Peer Behavior } & On & $\begin{array}{l}\text { Exposed to healthy eating habits, increasing } \\
\text { preference for healthy food by } 0.5 \% \text { per month. }\end{array}$ \\
\hline & Off* & $\begin{array}{l}\text { Exposed to unhealthy eating habits, decreasing } \\
\text { preference for healthy food by } 0.095 \% \text { per month. }\end{array}$ \\
\hline
\end{tabular}


for parameters. Figure 3 documents the types of meals the household is consuming by percentage when the model runs for two years (24 monthly time steps). The typical household is consuming far less than the recommended daily intake of nutritious foods, and this result tracks well with documented consumption habits for the residents of Detroit (Feeding America, 2016; Zenk et al., 2005).

\section{Parameter Uncertainty}

There are some model parameters that we have had to estimate because the secondary data was inconclusive or the value of an input variable was genuinely unknown. For these parameters, we tested the model with multiple runs, varying the parameter values incrementally. This technique, referred to as sensitivity analysis, allows the team to understand how these parameter assumptions affect the model behavior (MacFarlane, 1968).

\section{Cost of Healthy Meals}

There is some debate in the literature on the price difference between healthy and nonhealthy foods (Carlson \& Frazão, 2012; Zenk et al., 2005). Here, healthy foods are represented by fresh fruits and vegetables. Figure 4B demonstrates the model's sensitivity to the relatively more expensive costs of healthy foods. As determined by the model structure, the Percent of Healthy Food Consumed Graph shows that for the most variance in meal price, the model output does not shift significantly. This output is explained because the modeled household seeks to maximize its preference for healthy food, which is not influenced by perceptions of affordability. However, the Percent of Emergency Food Consumed is sensitive to meal cost, varying between $0.3 \%$ of total food consumed on the lowest end and $5.6 \%$ of the total food consumed on the high end.

Figure 3. Reference Mode Model Output and Sensitivity Analysis

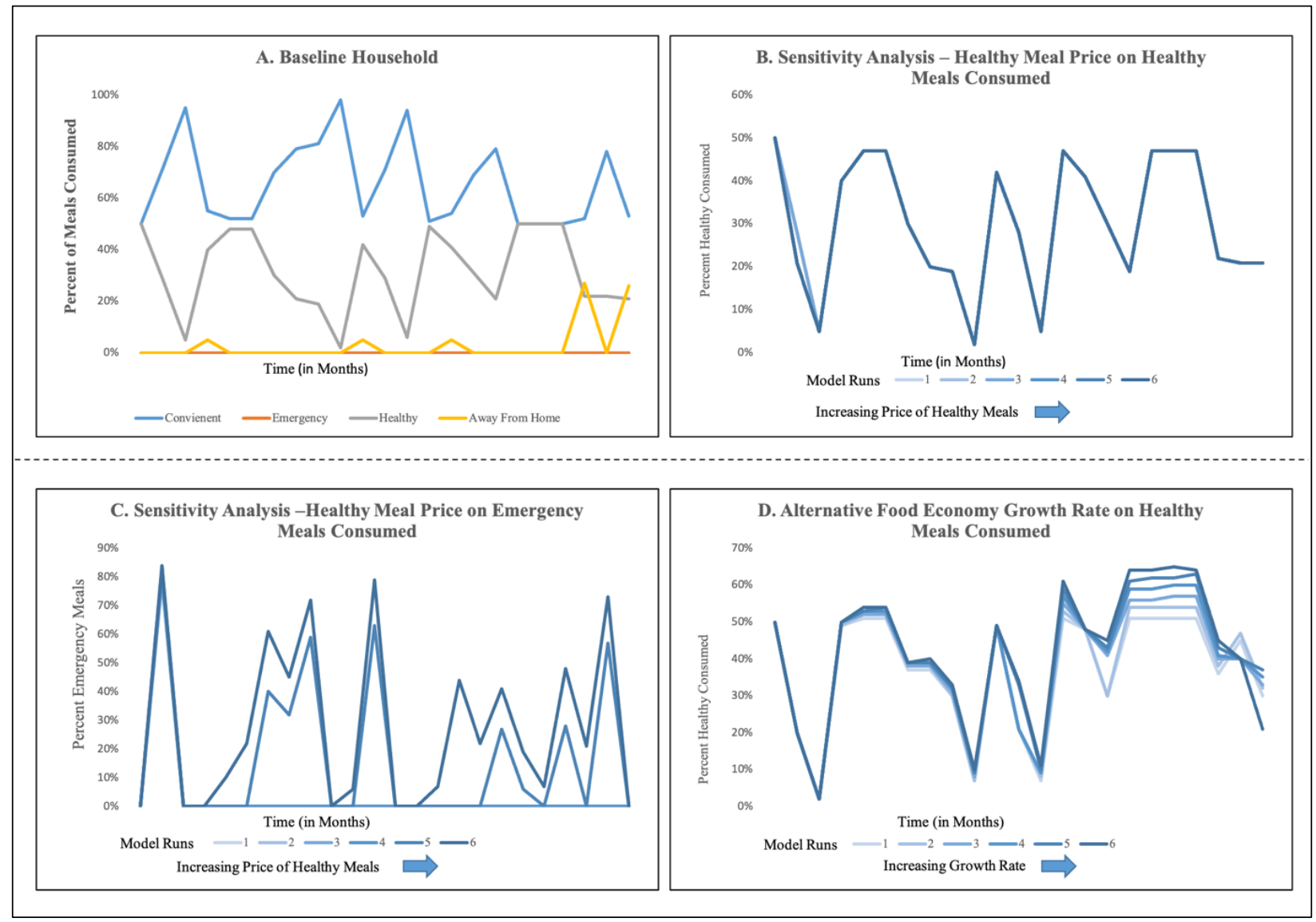


Figure 4. Scenario 1: Low Income, No Car, No Assistance, Variable Work Schedule

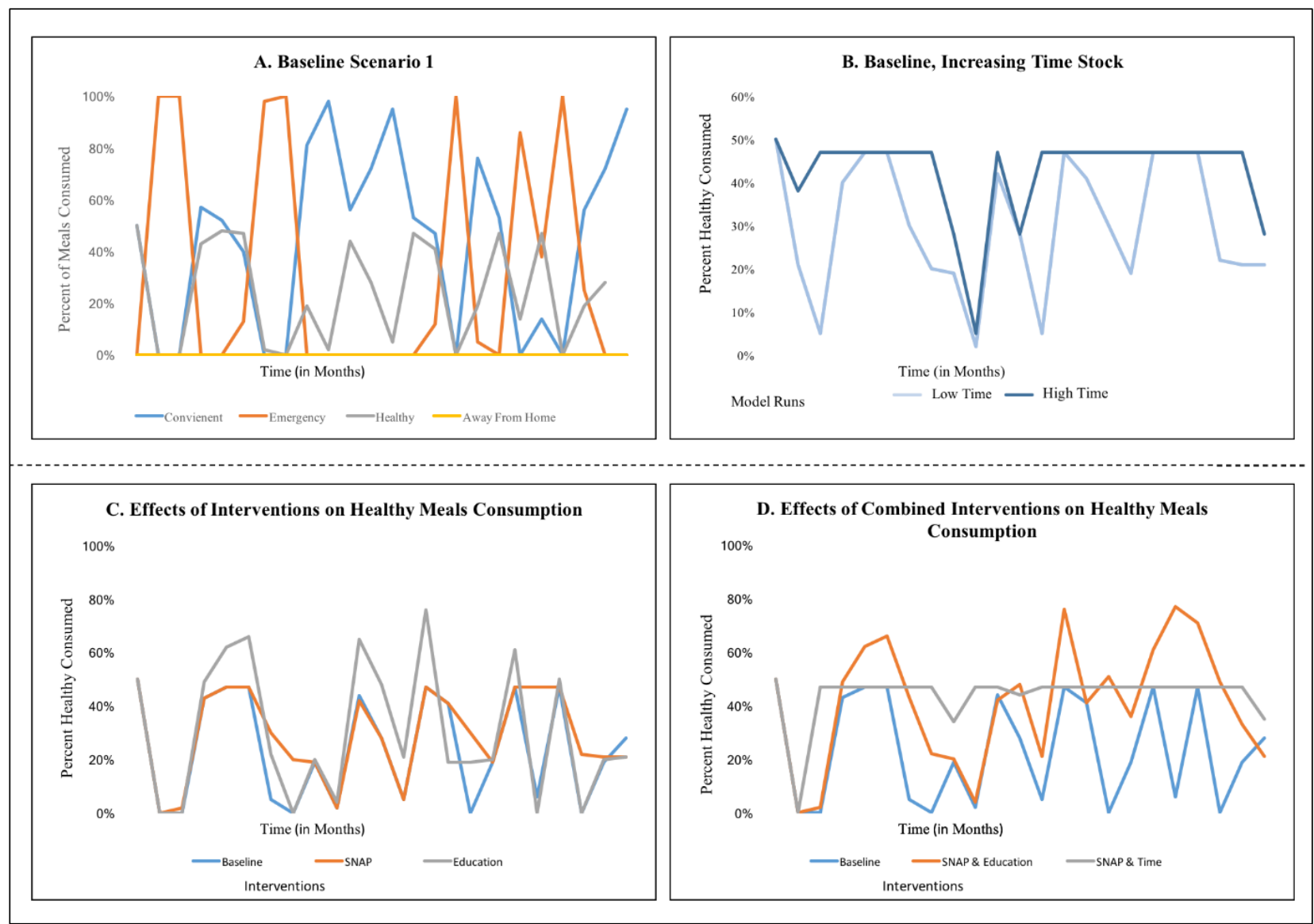

Alternative Food Economy Growth Rate

It is uncertain how the Alternative Food Economy (AFE) is evolving in the city of Detroit. Some stakeholders believed it to be growing at a rapid rate, while others did not. Figure 5D demonstrates the model's sensitivity to changes in this growth rate on the percentage of healthy foods consumed. The growth rate is modulated incrementally between $0 \%$ and $10 \%$ per year. Figure 5D demonstrates that increasing the growth rate increases the demand for healthy meals and decreases the number of healthy meals the household is required to travel long distances to procure. Increasing the growth rate also produces a small shift in the amount of 'away-from-home meals' the household consumes, as the household's preferences have changed, despite it still being time constrained. This behavior is due to a time delay between how quickly the AFE responds to increases in demand.
The growth rate is important because there is a feedback loop between FF\&V Preferences and the AFE: the more the household prefers healthy food, the more the AFE grows, and, in turn, the more the household will be exposed to healthy foods, changing its preferences.

\section{Scenario Results}

During the modeling workshop, stakeholders created scenarios using the model interface. To interpret the effectiveness of interventions, we have created a scenario space that describes the initial household conditions and documents the model behavior when different interventions are applied (see Table 1).

\section{Scenario 1}

Scenario 1 represents a Detroit household that is quite vulnerable to food and nutritional insecurity. 
The scenario simulates a household of three, which has one income earner making the minimum wage, with a highly variable work schedule. The household is not participating in any federal or state supplemental nutrition programs and does not have access to a vehicle. This variation in work schedule produces two constraints on the household, the first being the variation in income, and the second being the amount of time the household has to procure and consume meals. The difference in food consumption by type is driven by the ebbs and flows of this work schedule. Over the two years, this results in the household consuming 34\% emergency meals, $42 \%$ convenience meals, and $24 \%$ healthy meals.

Figure 4C and 4D demonstrate the effects of the interventions. Applying for and receiving SNAP benefits does marginally increase the number of healthy meals the household is consuming by a 6-percentage point difference. SNAP's most significant role in this scenario is reducing the number of emergency meals the household is consuming. In the intervention, emergency meals are replaced with convenience meals and not healthy meals due to access, time shortages, and preferences. Adding a healthy eating education program, which acts on preference for healthy food, increases the consumption of healthy meals by five percentage points. This intervention also increases the number of emergency meals the household consumes. This counterintuitive outcome is driven by the increased time and financial resources a household is required to use to meet this healthy eating goal. Because the inflow of financial and time resources is variable, in time steps where these resources are scarce, the household no longer has the time or financial resources to purchase less expensive meals. The healthy eating education program, which focuses on shifting household preferences, also influences the growth rate of the local food economy, and this marginally increases access and exposure to healthier food options.

Figure 5. Scenario 2: Mid-Low Income, Car, Variable Work Schedule

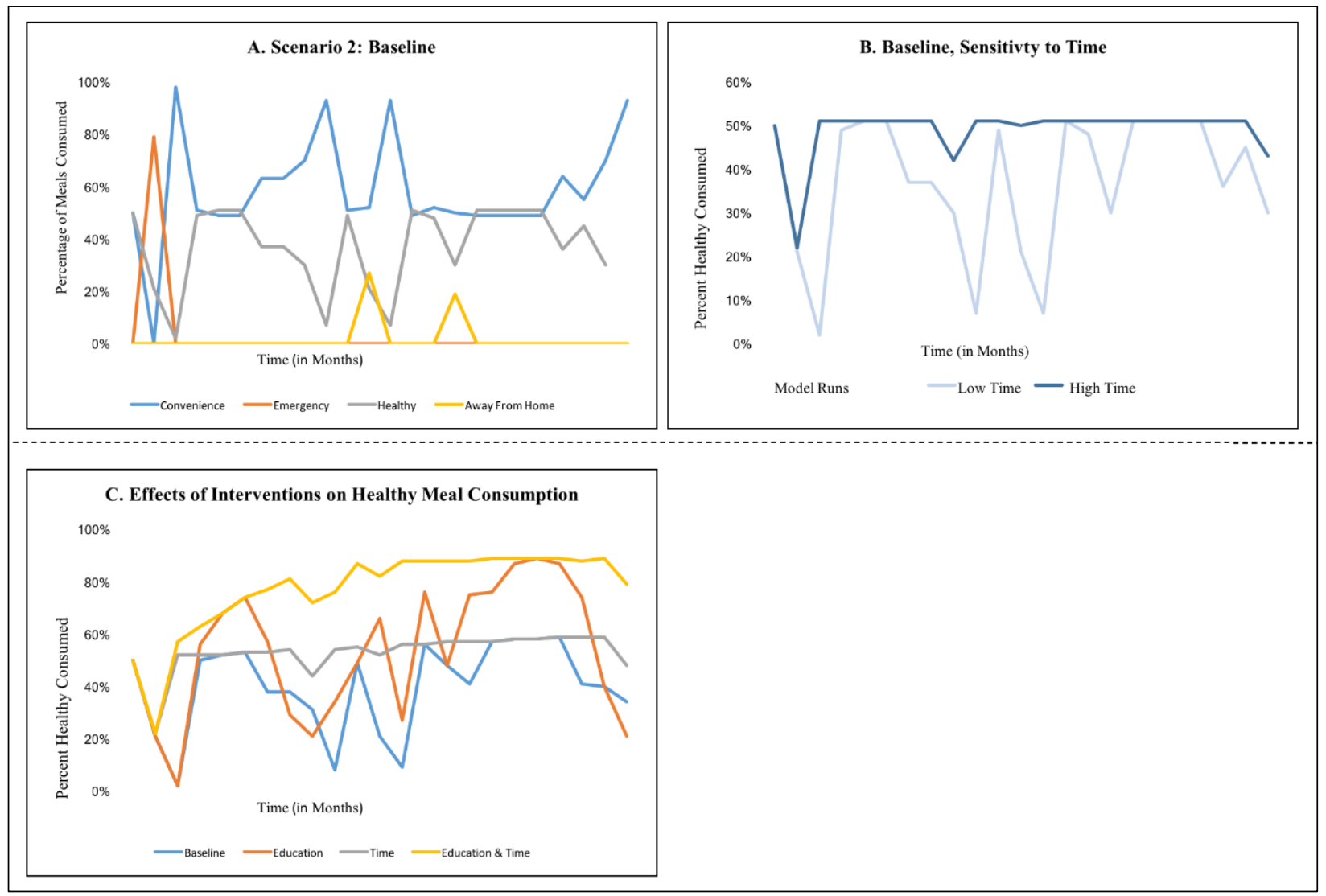


Figure 4D illustrates healthy eating consumption when the model is set to receive SNAP benefits and is allocated an additional hour for each day. This combination of household resources stabilizes the consumption of healthy foods. The extra hour per day represents interventions that save the household time, such as improvement of public transportation speed, development of organizational skills, or a change in family labor allocation.

\section{Scenario 2}

Scenario 2 represents a Detroit household that is vulnerable to food and nutritional insecurity. The scenario simulates a household of three, which has one income earner making US $\$ 12$ an hour, and a variable work schedule. The household is participating in the federal SNAP program and has access to a vehicle. The baseline run for this scenario, illustrated in Figure 5A, shows that the household is consuming $38 \%$ healthy meals, $56 \%$ convenience meals, $2 \%$ away-from-home meals, and $4 \%$ emergency meals. The variability of the diet is primarily driven by the variable work schedule, placing pressure on the time stock. Figure 5B shows how perceived time scarcity effects consumption decisions. Each model run in Figure 5B increases the time stock incrementally. The final model run (6) increases the time stock by one hour per day and reduces the variability and increases the quantity of healthy food consumed.

Figure $5 \mathrm{C}$ demonstrates the effects of various interventions on household healthy food consumption. The first intervention is a healthy eating education campaign that targets household food preferences. This intervention works to increase healthy meal consumption by ten percentage points, decrease convenience meals by 22 percentage points, and increase away-from-home meals by 12 percentage points. The increase in the use of awayfrom-home meals, which tend to be less healthy, is counterintuitive. It is caused by the increase in preferences for healthy meals and the household time stock remaining scarce. When the household perceives time scarcity, the household tries to consume a convenience meal; when none is available, the household consumes a prepared meal or awayfrom-home meal instead. The next intervention is a combination of additional time and the education component previously noted. This intervention has the effect of increasing healthy meal consumption by 34 percentage points, reducing convenience meals by 33 percentage points and reducing awayfrom-home meals by two percentage points. This combination intervention has the outcome of a reasonably consistent diet with an average of $75 \%$ of meals being healthy. The variability of the diet in this scenario is driven by the work schedule placing pressure on the time stock, and to a lesser extent, the variability in income. Figure $5 \mathrm{~B}$ shows how perceived time scarcity effects consumption decisions. Each model run in Figure 5B. increases the time stock incrementally. The final model run six (6) increases the time stock by one hour per day and reduces the variability of and increases the quantity of healthy food consumed. The variability of run six (6) in Figure 5B. is driven by the variability in income over the period.

\section{Scenario 3}

Scenario 3 represents a Detroit household that is vulnerable to food and nutritional insecurity. The scenario simulates a household of three, which has one income earner making US $\$ 18$ an hour and a variable work schedule. The household is participating in the federal SNAP program, though it is only periodically eligible for benefits, and has access to a vehicle. The baseline run for this scenario illustrated in Figure 6A shows that the household is consuming $26 \%$ healthy meals, $70 \%$ convenience meals, $5 \%$ away-from-home meals, and $0 \%$ emergency meals. The variability of the diet is due to the variable work schedule placing pressure on the time stock. Figure 6B shows how perceived time scarcity affects consumption decisions. Each model run in Figure 6B increases the time stock incrementally. The final model run (6) increases the time stock by one-hour per-day and reduces the variability and increases the quantity of healthy food consumed.

Figure 6C demonstrates the model output for various interventions for this scenario. The first run represents the baseline with no interventions. The second run (and first intervention) is a healthy eating education campaign targeted at increasing the household's awareness and preferences for healthy meals. For this scenario, the intervention 
increases healthy meal consumption by 13 percentage points, decreases convenience meal consumption by 25 percentage points, and increases away from home consumption by 12 percentage points. There was no change in emergency food consumption. The increase in away-from-home meal consumption, as in Scenario 2, may be counterintuitive, but is a result of the decrease in convenient meal purchasing and perceived time scarcity. The household recognizes that it is time-poor, and then wishes to consume a convenience meal, but with limited meals in its pantry, it chooses to eat a meal away from home. The third intervention combines the time intervention, adding an extra hour of perceived free time per day to the time stock, and the healthy eating education program. It increases healthy meals consumed by 38 percentage points, decreasing convenience meals by 36 percentage points, and decreasing away-from-home meal consumption by 2.5 percentage points.

\section{Participant Feedback on the Model}

Stakeholders identified three areas of concern with the model, the first being the nutritional composition of "Away from home/Prepared Meals." In the model interface, these meals are categorized as unhealthy. While research supports the finding that away-from-home meals are of lower nutritional value (Guthrie et al., 2002; Jekanowski, 1999; Stewart et al., 2004), this is on average and may not represent the preferences of some households for healthy prepared options. Secondly, there was extensive discussion in the workshop about the relative price of a healthy meal compared to a convenience meal. Sensitivity analysis demonstrates the effect of comparable price on model output and found that though it is important, it is not a major driver of nutritional food security status. The third concern with the model was that it lacked a feedback mechanism between changes in the Alternative Food Economy (AFE) and Preferences for

Figure 6. Scenario 3: Mid Income, Car, Variable Work Schedule

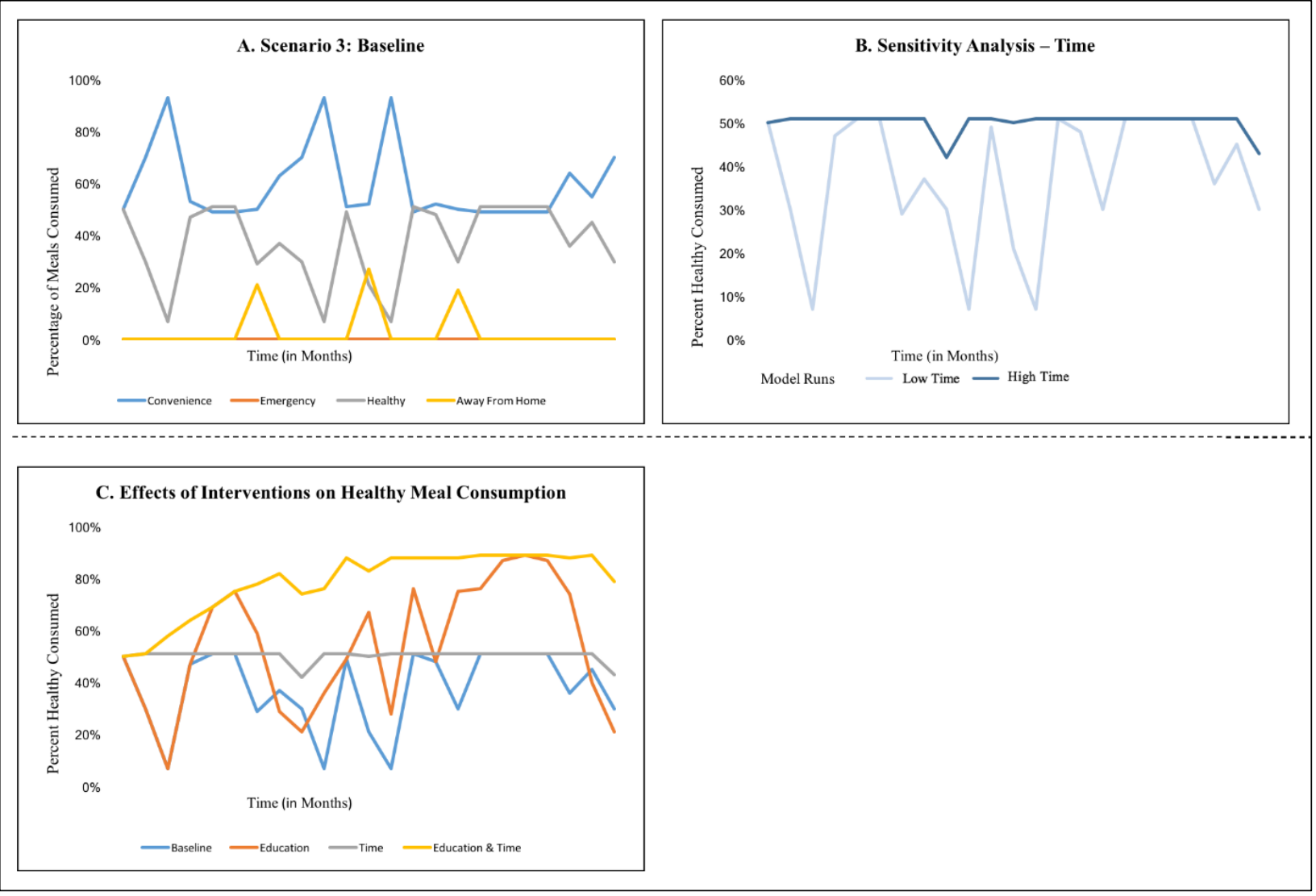


FF\&V. This feedback loop was added to reflect that as the AFE expands, it increases exposure to, and demand for, nutritious food. Overall, the stakeholder group felt that the proposed model accurately captured their views of the complexity of household food and nutritional insecurity.

\section{Discussion}

Our model results document how specific limitations govern the dynamics of household food and nutritional security. These limitations operate by restricting a household's ability to access opportunities for food security. As all three scenarios demonstrate, the effects of singular interventions are mostly ineffective because other limits temper the opportunities they create. For example, in Scenario 1 , the variability of the household's healthy eating behavior is being driven by the variability of the work schedule, both in terms of an income limit and time pressure limit. Applying a food income intervention is not fully effective, as time pressure is then the dominant limit. In another example, adding a vehicle to the household reduces the pressure of the time stock, but comes at a cost, reducing income available for meals and potentially reducing savings. We also document how healthy eating education can boost a household's healthy eating preferences, but in the absence of interventions to increase a household's access to healthy foods, economic status, or time, these preferences cannot be satisfied by the household. The results suggest that interventions are much more effective if they are designed to target multiple limits or drivers of food insecurity.

Much of the literature around household food security deals with what Campbell (1991) describes as the "social aspects of food security," focusing on household resources and characteristics of the food environment. This focus on the social aspects is evident in a literature review by Walker et al. (2010). Although useful for creating food security indicators and monitoring, this focus may lead to a limited understanding of the complexity and systemic factors that cause a household to experience food insecurity. Research that has included the experiential dimension of food security has done so through the use of food diaries and survey methods (Storberg-Walker, 2009; Wrigley et al., 2003,
2002). This approach has revealed implications for households living in different food environments but is limited in the number of studies and scope of dynamics that can be observed. An advantage of our modeling approach has been the ability to study the experiential dimensions of food security from stakeholder perspectives and simulate these dynamics over time. In our results section, we illustrated counterintuitive behavior, in which some interventions lead to an increase in away-from-home meal consumption or more reliance on emergency meal coping mechanisms. These behaviors were driven by system feedback and delayed effects between food availability and household preferences. This system behavior may reveal unintended consequences of interventions and programs that fail to include an experiential focus. Though the implications of this model are limited, it demonstrates the usefulness of separating social and experiential food security indicators. Contrasting the indicators more accurately captures the consequences of living in different food environments.

Our focus on experiential outcomes allows our model to take an expanded view of household resources-incorporating household knowledge, time availability, preferences, and income. We believe that documenting the interactions of these resources is a novel and necessary outcome of this research. The model output shows that households face periods of food insecurity when income and time availability fluctuate with variable work schedules. We were also able to merge research findings on behavioral health and food environments to explore the importance of time as a resource stock (Daly, 1996; Jabs \& Devine, 2006; Jabs, Devine, Bisogni, Farrell, Jastran, \& Wethington, 2007; McKenzie, 2014). Time affects the model as both a stock and a perception of time scarcity. As a resource stock, available time is a limit to the procurement of food items. This represents an interaction with the food environment through the physical distance to grocery stores and access to transportation. Our model, therefore, supports the incorporation of temporal distance and time-distance measures into the analysis of food environments and food security (McKenzie, 2014; Rose \& Richards, 2004). Secondly, a household's perception of the necessary time to cook, 
clean, and consume food leads households to choose alternative options for consumption, even if their food stock is plentiful. In our model, this leads to the use of potentially less healthy options and food spoilage. Our model explicitly assumes that the household drains their time resource stock when they must travel for a long-time procuring food; this then shapes how they perceive available time when they make consumption decisions. Coupling a time component with many of the other interventions has reinforcing effects, multiplying the effectiveness of interventions.

Further research is necessary to test the nature of these dynamics at different scales. It is also important to consider the macroscale dimensions of the CLD, notably the socio-political segment, which could affect the long-term system behavior through household actions shaping the food landscape.

\section{Limitations}

The system dynamics model presented in this article is based on an integration of stakeholder mental models with academic theory and secondary empirical data. Our stakeholder group mainly represented practitioner knowledge and expert testimony from years of experience working in the Detroit food system. A fair criticism of our process is that we did not include participants with first-hand experiential knowledge of food insecurity. The household decision process in our model is based on theory and our assumption that households would attempt to maximize the fulfillment of their healthy eating preferences. A group model-building process with food-insecure households could prove very advantageous and yield more system discoveries, as well as provide another source of validation for the model findings.

Another limitation is that although our model includes a representation of temporal distance as a function of transportation speed and distance, it is not geographically explicit. A geographically explicit model could introduce other elements into the temporal distance calculation, including congestion, road conditions, public transportation schedules, walkability, and safety. This could clarify the heterogeneous landscape of household food security in the city.
Our model may be limited in the way we approached intrahousehold dynamics. In the model, all household activities that require time, including all aspects of procuring, preparing, and cleaning up of meals, are attributed to the same time stock. Some research exists on how the shift in intrahousehold dynamics impacts food consumption and time allocation decisions though we did not find conclusive evidence to represent these effects in the model. This could be important, especially in circumstances in which households are utilizing emergency food coping mechanisms. Also, the model problematically assumes that the household is homogenous concerning eating preferences and dietary requirements. There could be an important delay in how a family adapts to shifts in preferences by the primary food decision-maker. For instance, a parent could purchase healthier meal options and receive feedback or resistance from family members, which may result in the food going to waste. This could result in reshaping the preferences of the purchaser in a balancing feedback loop. Furthermore, though using FF\&V as a proxy for healthy food preferences is useful in this context, there are of course healthy options that are both affordable and nonperishable.

\section{Potential Policy Implications}

Interpreting the model behavior can be useful for informing policy considerations. It should be done with the cautious understanding that the model is not meant to be predictive but used as a tool to better understand the interconnectedness of variables driving system behavior. Given the limitations outlined above, we believe there are policy and programmatic areas where the model can help inform the discussion.

Our model demonstrates that coupling a time component with many interventions has reinforcing effects, multiplying the impact of interventions. Conceptualizing a time intervention may be difficult, and further research is needed, but here we will point to some hypothetical interventions that may be considered. For instance, at the national level, food assistance programs could make allowances for additional costs of semiprepared healthy food options or assist with transportation. We believe this could help reduce household time pres- 
sure. Information and research on the marginal time savings and price premiums for such a program change are out of scope for this project but could reveal critical considerations. We also envision programs that assist people in understanding the true time it takes to prepare and consume healthy foods. It could be beneficial to link these programs to farmers markets and grocery stores where people are purchasing their groceries.

\section{Conclusions}

This modeling effort demonstrates the usefulness of using a participatory process to unpack a complex social issue. The research design enabled the modeling to be iterative and allowed participants to see the benefits of collaborative research and systems thinking. The qualitative CLD documented and explored stakeholder understanding and knowledge of systemic structural issues facing residents of Detroit and how the combination of these forces interacting may limit opportunities. The quantitative model allowed us to explore the experiential dimensions of food and nutritional security and test stakeholder assumptions of how various interventions should be structured and implemented. The system dynamics model demonstrated the multiple drivers of food insecurity at the household level for residents of Detroit. Some of these drivers have been extensively documented in the literature including; the barriers of access, characteristics of the food environment, and the limits of household income (Beaulac et al., 2009; Campbell, 1991; Lass, Stevenson, Hendrickson, \& Ruhf, 2003; McKenzie, 2014; Walker et al., 2010; Zenk et al., 2005). We are also able to support findings that a household's stock of available 'free time' and its perception of time are important factors in food-related decision making (Furst et al., 1996; Jabs \& Devine, 2006; McKenzie, 2014). Our model adds to the understanding that these behavioral dimensions and access barriers interact to limit household food security opportunities. The model's behavior demonstrates the necessity of taking an expanded view of household resources, one that includes aspects of time management and availability, food prices, knowledge, preferences, and peer behavior. We believe this research has explanatory power in why these resources should be integrated into measurements of food security, which is a novel and essential outcome.

\section{References}

Barlas, Y. (1996). Formal aspects of model validty and validation in system dynamics. System Dynamics Review: The Journal of the System Dynamics Society, 12(3), 183-210. https://doi.org/10.1002/(SICI)1099-1727(199623)12:3\%3C183::AID-SDR103\%3E3.0.CO;2-4

Beaulac, J., Kristjansson, E., \& Cummins, S. (2009). A systematic review of food deserts, 1966-2007. Preventing Chronic Disease, 6(3), A105. Retrieved from https://pubmed.ncbi.nlm.nih.gov/19527577/

Bellows, A. C., \& Hamm, M. W. (2002). U.S.-Based Community Food Security: Influences, Practice, Debate. Journal for the Study of Food and Society, 6(1), 31-44. https://doi.org/10.2752/152897902786732725

Brunner, T. A., van der Horst, K., \& Siegrist, M. (2010). Convenience food products. Drivers for consumption. Appetite, 55(3), 498-506. https://doi.org/10.1016/j.appet.2010.08.017

Campbell, C. C. (1991). Food insecurity: A nutritional outcome or a predictor variable? The Journal of Nutrition, 121(3), 408-415. https://doi.org/10.1093/jn/121.3.408

Carlson, A., \& Frazão, E. (2012). Are healthy foods really more expensive? It depends on how you measure the price (Economic Information Bulletin No. 96). USDA Economic Research Servivce. https://doi.org/10.2139/ssrn.2199553

Cawley, J. (2004). An economic framework for understanding physical activity and eating behaviors. American Journal of Preventive Medicine, 27(3 SUPPL.), 117-125. https://doi.org/10.1016/j.amepre.2004.06.012

Clifton, K. J. (2004). Mobility strategies and food shopping for low-income families: A case study. Journal of Planning Education and Research, 23(4), 402-413. https://doi.org/10.1177/0739456X04264919

Conner, D. S., \& Levine, R. (2007). Circles of association: The connections of community-based food systems. Journal of Hunger \& Environmental Nutrition, 1(3), 5-25. https://doi.org/10.1300/J477v01n03 02

Connors, M., Bisogni, C. A., Sobal, J., \& Devine, C. M. (2001). Managing values in personal food systems. Appetite, 36(3), 189-200. https://doi.org/10.1006/appe.2001.0400 
Daly, K. J. (1996). Families \& time: Keeping pace in a hurried culture (7th ed.). Thousand Oaks, CA: Sage. https://doi.org/10.4135/9781483327792

Feeding America. (2016). Map the Meal Gap 2016: Food insecurity and child food insecurity estimates at the county level. Feeding America. Retrieved from https://www.feedingamerica.org/sites/default/files/research/map-the-mealgap/2014/map-the-meal-gap-2014-exec-summ.pdf

Fleischer, N. L., Liese, A. D., Hammond, R., Coleman-Jensen, A., Gundersen, C., Hirschman, J., ... Jones, S. J. (2017). Using systems science to gain insight into childhood food security in the United States: Report of an expert mapping workshop. Journal of Hunger \& Environmental Nutrition, 13(3), 1-23. https://doi.org/10.1080/19320248.2017.1364194

Furst, T., Connors, M., Bisogni, C. A., Sobal, J., \& Falk, L. W. (1996). Food choice: A conceptual model of the process. Appetite, 26(3), 247-266. https://doi.org/10.1006/appe.1996.0019

Gofton, L. (1995). Convenience and the moral status of consumer practices. In D. W. Marshall (Ed.), Food choice and the consumer (pp. 152-181). Glasgow: Blackie Academic \& Professional.

Guthrie, J. F., Lin, B.-H., \& Frazao, E. (2002). Role of food prepared away from home in the American diet, 1977-78 versus 1994-96: Changes and consequences. Journal of Nutrition Education and Behavior, 34(3), 140-150. https://doi.org/10.1016/S1499-4046(06)60083-3

Guy, C., Clarke, G., \& Eyre, H. (2004). Food retail change and the growth of food deserts: A case study of Cardiff. International Journal of Retail \& Distribution Management, 32(2), 72-88. https://doi.org/10.1108/09590550410521752

Hamm, M. W., \& Bellows, A. C. (2003). Community food security and nutrition educators. Journal of Nutrition Education and Behavior, 35(1), 37-43. https://doi.org/10.1016/S1499-4046(06)60325-4

Hendrickson, D., Smith, C., \& Eikenberry, N. (2006). Fruit and vegetable access in four low-income food deserts communities in Minnesota. Agriculture and Human Values, 23(3), 371-383. https://doi.org/10.1007/s10460-006-9002-8

Hillier, A., Cannuscio, C. C., Karpyn, A., McLaughlin, J., Chilton, M., \& Glanz, K. (2011). How far do low-income parents travel to shop for food? Empirical evidence from two urban neighborhoods. Urban Geography, 32(5), 712-729. https://doi.org/10.2747/0272-3638.32.5.712

Hirsch, G. B., Levine, R., \& Miller, R. L. (2007). Using system dynamics modeling to understand the impact of social change initiatives. American Journal of Community Psychology, 39(3-4), 239-253. https://doi.org/10.1007/s10464-007-9114-3

Hodbod, J., \& Eakin, H. (2015). Adapting a social-ecological resilience framework for food systems. Journal of Environmental Studies and Sciences, 5(3), 474-484. https://doi.org/10.1007/s13412-015-0280-6

Hovmand, P. S., Ford, D. N., Flom, I., \& Kyriakakis, S. (2009). Victims arrested for domestic violence: Unintended consequences of arrest policies. System Dynamics Review, 25(3), 161-181. https://doi.org/10.1002/sdr.418

Jabs, J., \& Devine, C. M. (2006). Time scarcity and food choices: An overview. Appetite, 47(2), $196-204$. https://doi.org/10.1016/j.appet.2006.02.014

Jabs, J., Devine, C. M., Bisogni, C. A., Farrell, T. J., Jastran, M., \& Wethington, E. (2007). Trying to find the quickest way: Employed mothers' constructions of time for food. Journal of Nutrition Education and Behavior, 39(1), $18-25$. https://doi.org/10.1016/j.jneb.2006.08.011

Jekanowski, M. D. (1999). Causes and consequences of fast food sales growth. USDA ERS Food Review, 22(1). Retrieved from https://ageconsearch.umn.edu/record/266201/files/FoodReview-204.pdf

Kirkwood, C. W. (1998). System dynamics methods: A quick introduction. College of Business, Arizona State University. Retrieved from https://www.nutritionmodels.com/papers/Kirkwood1998.pdf

Lamine, C. (2015). Sustainability and resilience in agrifood systems: Reconnecting agriculture, food and the environment. Sociologia Ruralis, 55(1), 41-61. https://doi.org/10.1111/soru.12061

Lass, D., Stevenson, G. W., Hendrickson, J., \& Ruhf, K. (2003). CSA Across the Nation: Findings from the 1999 CSA Survey. Madison, WI: Center for Integrated Agricultural Systems, University of Wisconsin-Madison. Retrieved from http:/ / www.cias.wisc.edu/economics/csa-across-the-nation-findings-from-the-1999-and-2001-csa-surveys/

MacFarlane, A. G. J. (1968). Introduction to system dynamics. Electronics \& Power, 14(1), 42. https://doi.org/10.1049/ep.1968.0042 
Maxwell, D. G. (1996). Measuring food insecurity: The frequency and severity of "coping strategies." Food Policy, 21(3), 291-303. https://doi.org/10.1016/0306-9192(96)00005-X

McKenzie, B. S. (2014). Access to supermarkets among poorer neighborhoods: A comparison of time and distance measures. Urban Geography, 35(1), 133-151. https://doi.org/10.1080/02723638.2013.856195

Olabisi, L. S. (2013). Participatory modeling in environmental systems. In Proceedings of the $31^{\text {st }}$ International Conference of the System Dynamics Society, Cambridge, MA.

Pothukuchi, K. (2011). The Detroit food system report 2009-2010. Detroit Food Policy Council. Retrieved from https://digitalcommons.wayne.edu/urbstud frp/6/

Rose, D., \& Richards, R. (2004). Food store access and household fruit and vegetable use among participants in the US Food Stamp Program. Public Health Nutrition, 7(8), 1081-1088. https://doi.org/10.1079/PHN2004648

Stave, K. A. (2002). Using system dynamics to improve public participation in environmental decisions. System Dynamics Review, 18(2), 139-167. https://doi.org/10.1002/sdr.237

Stave, K. A. (2003). A system dynamics model to facilitate public understanding of water management options in Las Vegas, Nevada. Journal of Environmental Management, 67(4), 303-313. https://doi.org/10.1016/S0301-4797(02)00205-0

Sterman, J. D. (2000). Learning in and about complex systems. Reflections: The SoL Journal, 1(3), 24-51. Retrieved from https://www.solonline.org/resources/

Sterman, J. D. (2001). System dynamics modeling: Tools for learning in a complex world. California Management Review, 43(4), 8-25. https://doi.org/10.2307/41166098

Stewart, H., Blisard, W. N., Bhuyan, S., \& Nayga Jr, R. M. (2004). The demand for food away from home: Full-service or fast food? USDA Economic Research Service (Agricultural Economic Report No. 829). https://doi.org/10.22004/ag.econ.33953

Storberg-Walker, J. (2009). Integrative literature reviews: Heterodox economics, social capital, and HRD: Moving beyond the limits of the neoclassical paradigm. Human Resource Development Review, 8(1), 97-119. https://doi.org/10.1177/1534484309332616

Story, M., Hamm, M. W., \& Wallinga, D. (2009). Research and action priorities for linking public health, food systems, and sustainable agriculture: Recommendations from the Airlie Conference. Journal of Hunger \& Environmental Nutrition, 4(3-4), 477-485. https://doi.org/10.1080/19320240903351497

U.S. Department of Agriculture, Food and Nutrition Service. (n.d.). Supplemental Nutrition Assistance Program—Eligibility. Retrieved October 1, 2017, from https://www.fns.usda.gov/snap/recipient/eligibility

U.S. Department of Health and Human Services \& U.S. Department of Agriculture. (2015). 2015-2020 dietary guidelines for Americans ( $8^{\text {th }}$ ed.). Retrieved from https://health.gov/our-work/food-nutrition/previous-dietary-guidelines/2015

Van den Belt, M. (2004). Mediated modeling: A system dynamics approach to environmental consensus building. Island Press.

Walker, R. E., Keane, C. R., \& Burke, J. G. (2010). Disparities and access to healthy food in the United States: A review of food deserts literature. Health \& Place, 16(5), 876-884. https://doi.org/10.1016/j.healthplace.2010.04.013

Widener, M. J., Farber, S., Neutens, T., \& Horner, M. W. (2013). Using urban commuting data to calculate a spatiotemporal accessibility measure for food environment studies. Health \& Place, 21, 1-9. https://doi.org/10.1016/j.healthplace.2013.01.004

Wrigley, N., Warm, D., \& Margetts, B. (2003). Deprivation, diet, and food-retail access: Findings from the Leeds "food deserts" study. Environment and Planning A, 35(1), 151-188. https://doi.org/10.1068/a35150

Wrigley, N., Warm, D., Margetts, B., \& Whelan, A. (2002). Assessing the impact of improved retail access on diet in a 'food desert': A preliminary report. Urban Studies, 39(11), 2061-2082. https://doi.org/10.1080/0042098022000011362

Zenk, S. N., Lachance, L. L., Schulz, A. J., Mentz, G., Kannan, S., \& Ridella, W. (2009). Neighborhood retail food environment and fruit and vegetable intake in a multiethnic urban population. American Journal of Health Promotion, 23(4), 255-264. https://doi.org/10.4278/ajhp.071204127

Zenk, S. N., Schulz, A. J., Hollis-Neely, T., Campbell, R. T., Holmes, N., Watkins, G., ... Odoms-Young, A. (2005). Fruit and vegetable intake in African Americans: Income and store characteristics. American Journal of Preventive Medicine, 29(1), 1-9. https://doi.org/10.1016/j.amepre.2005.03.002 